\title{
Research on Countermeasures for the Ecotourism Cooperation Zone in Zhejiang, Anhui, Fujian and Jiangxi Provinces
}

\author{
Jianming Wang \\ School of Business Administration \\ Zhejiang University of Finance and Economics \\ Hangzhou, China 310018
}

\author{
Qingfang Zhao \\ School of Business Administration \\ Zhejiang University of Finance and Economics \\ Hangzhou, China 310018
}

\begin{abstract}
The 13th Five-Year Plan for Tourism Development is committed to the concept of innovative, coordinated, green, open, and shared development. On the basis of this program, the State Council has stressed the leading role of Zhejiang Province in creating the Zhejiang-Anhui-Fujian-Jiangxi Ecotourism Cooperation Zone. This paper, taking the Internet plus tourism as the opportunity of the times, provides four effective, pioneering and institutional countermeasures-creating special tourism, innovating tourism development mechanism, implementing driving strategy of large scenic area and shaping the tourism brand based on the interpretation and analysis of the 13th Five-Year Plan for Tourism Development and related data. And then the ecotourism cooperation zone features not only looking at the scenery, taking a photo and eating a meal, but also a process from the mountains to the sea, from the city to the rural area, a green industrial linkage of primary, secondary, and tertiary industries as well as a multi-industry complex highly integrated with the new way of life.
\end{abstract}

Keywords-ecotourism cooperation zone; green development; Zhejiang-Anhui-Fujian-Jiangxi; the Internet plus tourism

\section{INTRODUCTION}

The 13th Five-Year Plan for Tourism Development, promulgated by the State Council on December 26,2016, defines the general train of thought, basic objectives, main tasks and safeguarding measures for tourism development during the 13th Five-year Plan (2016-2020). Column 7(Special Tourism Function Area Promoting Plan )-Cultivating Crossregion Special Tourism Function Area clearly points out to create and bolster the Zhejiang-Anhui-Fujian-Jiangxi Ecotourism Cooperation Zone. This ecotourism cooperation zone, occupying Huangshan, Shangrao and Hangzhou central places, promoting the Chizhou, Anqing, Xuancheng, Sanming, Jingdezhen, Quzhou and other urban areas tourism collaborative development, involves Zhejiang, Fujian, Anhui, Jiangxi provinces with a total area of 220,000 square kilometers. $\mathrm{Wu}$ Wenxue, deputy director of the National Tourism Administration pointed out that the establishment of Zhejiang-Anhui-Fujian-Jiangxi Ecotourism Cooperation Zone is to implement the general secretary of Comrade Xi Jinping "Lucid waters and lush mountains are invaluable assets" theory and step up efforts to support national regional development strategy of major initiatives [1]. Four provinces jointly participate in the ecotourism trial, promoting the tourism industry clustering, accelerating the construction of the East China World Heritage Scenic Road, which will create a regional tourism depth of cooperation precedent.

As the leader of the ecotourism cooperative zone, Zhejiang Province has attached great importance to the development of tourism in recent years. In 2004, Comrade Xi Jinping put forward "constructing Zhejiang a strengthened tourism economy province", a major decision-making arrangement during his work in Zhejiang [2]. Ten years later, the comprehensive tourism strength of the province continued increasing by closely following this strategy, the total number of tourists growing from 110 million in 2004 to 584 million in 2016, the total tourism revenue getting a record of RMB809.32 billion in 2016, an average annual growth of 16 percent from 2004 [3]. What were more, the period covered by the 12 th Five-Year Plan came to a close in 2015 and Zhejiang had gotten a total income of RMB 713.91 billion in tourism industry, accounting for 6.83 percent of the province's GDP, far higher than the other three provinces (More information in "Table I") [4]. Despite a significant growth, tourism in China (Especially in Zhejiang, Anhui, Fujian and Jiangxi Provinces), in general, falls short of people's demand. All above, the development of ecotourism in Zhejiang must be raised to a strategically national level, actively accelerating the construction of Zhejiang-Anhui-Fujian-Jiangxi Ecotourism Cooperation Zone. No doubt that Zhejiang Province has a strong modeling effect on others, therefore, this research is mainly based on Zhejiang Province.

TABLE I. TOTAL TOURISM REVENUE IN ZHEJIANG, ANHUI, FuJIAN AND JIANGXI PROVINCES

\begin{tabular}{|c|c|c|c|}
\hline \multirow{2}{*}{ Province } & \multicolumn{3}{|c|}{ Related Data } \\
\cline { 2 - 3 } & Total tourism revenue(Billion) & $\begin{array}{c}\text { Growth } \\
\text { rate(Percent) }\end{array}$ \\
\cline { 2 - 3 } & $\mathbf{2 0 1 5}$ & $\mathbf{2 0 1 6}$ & 13.4 \\
\hline Zhejiang & RMB 713.91 & RMB 809.32 & 19.7 \\
\hline Anhui & RMB 412.02 & RMB 493.24 & 25.3 \\
\hline Fujian & RMB 314.15 & RMB 393.52 & 37.6 \\
\hline Jiangxi & RMB 363.77 & RMB 499.30 & \\
\hline
\end{tabular}

As the Jiangxi Provincial Bureau of Statistics does not give the final data, so it is calculated with given data by the author. 


\section{COUNTERMEASURES FOR THE ECOTOURISM} COOPERATION ZONE

Faced with the unknown challenges and new opportunities brought by the new normal of economic, as well as the rising demand for tourism (Especially premium and creative tourist programs and services) and the expectation of new tourist products and novel forms of tourism, we need to implement the concept of innovative, coordinated, green, open, and shared development and initiatively embrace this masstourism era. For the Zhejiang-Anhui-Fujian-Jiangxi Ecotourism Cooperation Zone, we can start with the two aspects of supply and demand. First, it is necessary to preserve the current developments and concern about the growth of the tourism industry, meeting the individual and diverse demands of travel; Second, Zhejiang Province and the other three should update and optimize the supply of tourism products, promoting the key groups' tourist consumption (More information in "Fig. 1"). Countermeasures include:

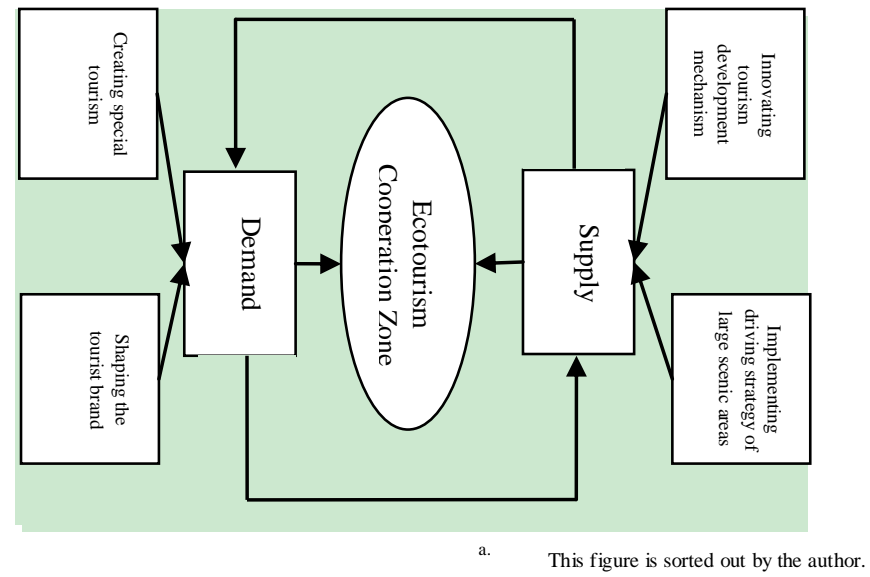

Fig. 1. Countermeasures for the Zhejiang-Anhui-Fujian-Jiangxi Ecotourism Cooperation Zone.

\section{A. Creating special tourism}

Tourism consumption is comprehensive consumption, final consumption, multi-level consumption and sustainable consumption [6]. It plays an irreplaceable role in expanding domestic demand, especially in expanding consumer demand. Concerning about development of new normal of tourism, we should focus on the cultivation of cultural and creative, oceanisland, rural agriculture slow life and green forest health tourism.

1) Cultivating cultural and creative tourism (Heading 3): "Creativity"is one of the keywords of 21st century. No.41 Document of State Council unveiled "Trillion Industry "policy, which put forward "enriching tourist cultural connotation" and " focusing on creating 50 cultural tourism demonstration areas till 2017" requirements for the first time in 2009. The rise of cultural and creative industries has opened up a whole world for many provinces and cities to seize the new highland of industry [3].Taking the Zhejiang Province as an example, the G20 2016 Hangzhou Summit, 2022 Hangzhou Asian Games and Variety show "Dad, where are we going", "Running man" etc. give opportunities to develop "Most Memorable Is Hangzhou", "Green Games", "Running man" and other culture and sports torism, relying on Huace Limited by Share Ltd, Songcheng Group Holdings Limited, China media, Zhejiang star-TV and other well-known cultural and creative enterprises. Animation industry is an important part of the cultural and creative industries, Hangzhou government puts forward the goal of "Making Hangzhou the whole country's cultural and creative industry center", and China Animation Museum, China Animation Festival is officially arranging preparatory work in Hangzhou.

2) Developing rural agriculture slow life tourism: In 2015, urban and rural residents per capita disposable income ratios of Zhejiang, Anhui, Fujian and Jiangxi were 2.07, 2.49, 2.41, 2.38 [5], suggesting that not only Zhejiang has achiveved the most balanced development between urban and rural,but also shows that there are still strong space for tourism development in other rural areas (More information in "Table II"). Depending on local natural and human resources, the ecological system and cultural heritage protection integrity, to achieve the integration of landscape-forest-lake-mountain, with features of "slow theme" rural tourism product system. In the process, we must emphasis "agriculture" as the basis for the ecotourism. Develop the characteristic and advantageous industries according to local conditions, striving to realize the unification of economic, social and ecological benefits, being a new engine for the transformation and updating of rural areas, agriculture and farmers. We should also be committed ourselves to following the green development concept and the law of rural development.

TABLE II. URban AND RURAL RESIDENTS PER CAPITA DisPosable RATIOS IN 2015

\begin{tabular}{|c|c|c|c|}
\hline \multirow{2}{*}{ Province } & \multicolumn{3}{|c|}{ Related Data } \\
\cline { 2 - 4 } & $\begin{array}{c}\text { Urban residents per } \\
\text { capita disposable } \\
\text { income }\end{array}$ & $\begin{array}{c}\text { Rural residents per } \\
\text { capita disposable } \\
\text { income }\end{array}$ & Ratio \\
\hline Zhejiang & RMB 43714.48 & RMB 21125.00 & 2.07 \\
\hline Anhui & RMB 26935.76 & RMB 10820.73 & 2.49 \\
\hline Fujian & RMB 33275.34 & RMB 13792.70 & 2.41 \\
\hline Jiangxi & RMB 26500.12 & RMB 11139.08 & 2.38 \\
\hline
\end{tabular}

Since the National Bureau of Statistics of China hasn't re leased the data in 2016, so the data in 2015 are used as a reference.

b. This table is sorted out by the author.

3) Promoting blue ocean-island tourism: Zhejiang Province has a coastline of 6486.24 kilometers, accounting for $20.3 \%$ of the Chinese, followed by Fujian Province with the terrestrial coastline of 3752 kilometers [7]. Anhui and Jiangxi provinces also have many river systems, which promote the development of the blue ocean-island tourism. As far as Zhejiang Province is concerned, the development of marine economy and the construction of "Zhejiang on the Sea" are the potentials, advantages and hope. Actively boost efforts to develop the cruise, yacht, leisure island, ocean exploration and meditation and other high-end tourism products,constructing a number of marine tourism areas with Zhejiang characteristics, 
cultivating a good many leisure tourism islands and fishing villages,to form diversified and competitive tourist routes in Zhejiang ocean.Besides, as Zhejiang is adjacent to Fujian, we can interconnec and set up a platform for cooperation in the development of marine islands. We will actively promote the integration of the Yangtze River Delta region and implement the 144-hour free transit visa policy in Shanghai, Jiangsu and Zhejiang provinces to explore the formation of regional cooperation and long-term mechanism.

4) Accelerating green forest health tourism: According to related statistics, the forest coverage rates of Zhejiang, Anhui, Fujian and Jiangxi were 59.1\%, 27.5\%, 66.0\%, 60.0\% in 2015 [5], demonstrating that these provinces have the advantages of developing forest health tourism(More information in "Table III"). With the rapid development of urbanization process, the negative effects of environmental pollution, urban life and working on people's physical and mental health are becoming increasingly prominent.Experiencing ecology, closing to nature and recovering to original simplicity through the promotion of forest landscape and forest restoration, construction of forest road and development of forest products, we also can accelarate transformation and upgrading from the felling trees to enjoy tree, from sightseeing to health in an effective way to increase peasants income. For Zhejiang, departments at all levels promote the construction of ecological civilization with "Trillion Industry" requirements, carrying out "Lucid waters and lush mountains are invaluable assets"concept.

TABLE III. FOREST COVERAGE RATES IN 2015

\begin{tabular}{|c|c|c|}
\hline \multirow{2}{*}{ Province } & \multicolumn{2}{|c|}{ Related Data } \\
\cline { 2 - 3 } & Forest area(Million $\mathbf{h m}^{2}$ ) & Rate (Percent) \\
\hline Zhejiang & 6.01 & 59.1 \\
\hline Anhui & 3.80 & 27.5 \\
\hline Fujian & 8.01 & 66.0 \\
\hline Jiangxi & 10.02 & 60.0 \\
\hline
\end{tabular}

Since the National Bureau of Statistics of China hasn't re leased the data in 2016, so the
data in 2015 are used as a reference. data in 2015 are used as a reference.
This table is sorted out by the author.

\section{B. Shaping the tourist brand}

At present, China's tourism industry has entered an era of vacation leisure, facing the upgrading from traditional extensive mode to green exquisite brand mode [8]. Behind the powerful tourism economic hides the problem of regional imbalanced development, especially during the Golden Week, huge crowds of people in some traditional while a deserted place in some new scenic areas. This requires the tourism industry to create a strong tourism brand.

1) Developing tourist goods and services: Tourist shopping is an important part of the travel experience as well as an important element of the tourism six elements [6], with a complete physical characteristics of tourist destinations.We will support a number of tourist commodities and service production bases, tourist commodities distribution centers and special commercial blocks, improving the functions of finance, logistics and other service. Pay attention to creative design of tourist products, strengthen protection of intellectual property rights and Zhejiang time-honored brand, maintaining the exuberant vitality of market.

2) Establishing brand marketing system: Further strengthen marketing and infrastructure system.The establishment of three-dimensional brand marketing system "Picturesque Zhejiang", the introduction of policies to promote the development of oversea tourism are to improve the transportation, navigation, toilets, currency exchange, information consultation and other public services [9]. With the help of G20 summit, Hangzhou Asian Games and Zhejiang TV popular variety show and other publicity effect, we can speed up the construction of " Picturesque Zhejiang "brand, promote tourism standardization, strengthen the tourism market supervision and accelerate propaganda work of brand marketing.

\section{Innovating tourism development mechanism [10]}

Personalization and quality are the inevitable trend of the era of mass- tourism. During 13th Five-Year (2016-2020), the development of tourist services and supply-system, especially public service products must be continuously optimized, to meet the consumers' demand and improve the tourism satisfaction. The 13th Five-Year Plan of Zhejiang put forward to vigorously implement the "Internet plus" project, deepening the integration of tourism industry and the Internet, and further enhancing green development innovation mechanism .

1) The "tourism plus" and "Internet plus"initiatives: Explore the establishment of tourism basic database and trip information sharing mechanism, construct and improve tourism industry information service platform and tourist-flow dynamic monitoring system. Zhejiang, on the one hand, actively develops tourism e-commerce, on the other hand, it encourages and supports the development of Internet science and technology to enhance tourism management. What's, we will encourage holistic tourism destinations development and the "tourism plus" program, and vigorously develop rural tourism, industrial tourism, culture tourism, and seniors and health tourism [11]. Those programs, combined with the "Internet plus" initiative, are designed to promote the integration of the primary, secondary and tertiary industries through tourism growth. To upgrade tourism will be a good way to improve the economy, both in efficiency and in quality.
2) Tourist transportation: Multi-dimensional, interconnected, green, intelligent modern tourism Sea-AirLand transportation system is being formed. To speed up the construction of high-rail,"traffic circle in one hour", is to further enhance the convenience of inter provincial links, and vigorously strengthen international tourism interoperability. Promote the province-level road passenger-station to develop into a local tourist distribution center, and guide scenic areas to build new and renovated tourist centers in moderate scale. We will strengthen cooperation between Zhejiang, Anhui, Fujian and Jiangxi, promoting regional integration in the Yangtze River Delta.Under the premise of civilized management of tourism market, we can push ahead the 
construction of tourism credit system, and explore the green tourism transportation card for the four provinces and even more extensive places.

3) Tourist quality: We will step efforts to improve infrastructure such as tourist attractions, parking lots, tourist centres, green streets, tourist signs, highways, service areas, caravans and self-driving camps. By 2020, more than 10 thousand new and renovated tourist toilets will be built, 120 thousand new parking lots will be built and rebuilt, 10 thousand kilometres of bicycle riding green roads will be built, and 100 new self-driving and caravans integrated camps will be built [10].According to the 13th Five-Year Plan, by 2020 , we will implement free $\mathrm{WiFi}$ in all $3 \mathrm{~A}$-level scenic area and the province-level tourism resort,and electronic intelligent tour guide explanation, online booking, electronic ticket verification,credit card payment and mobile payment, information-push function in all 4A-level scenic areas and the province-level tourism resort to enhance tourists' experience [10].

4) Tourist security: Construct a tourist security and riskwarning system,as well as a tourism information-release mechanism in key areas [10]. At the same time, we need to vigorously carry out color management and sunshine kitchen, so that visitors eat safely. The establishment of a green certification system, sound green hotels, green buildings [12]; the construction of tourism environmental monitoring and warning mechanism and green development supervision system; the improvement of the ecological protection areas and ecological fragile areas are all necessary to be done.

\section{Implementing driving strategy of large scenic areas}

The overall development of Zhejiang-Anhui-FujianJiangxi Ecotourism Cooperation Zone is "ne circle, three pieces, five groups, ten lines". "One circle" refers to the Hangxinjing expressway area, at the core area of ecological protection demonstration area. "Three pieces" are the "Mount Jiuhua of Mount Tianzhu-Mount Huangshan-Chunan", the"Shangrao-Quzhou", and "Wuyishan-Taining-Lishui". "Five groups" means 5 boundaries of Zhejiang-Anhui, Zhejiang-Fujian, Zhejiang-Jiangxi, Anhui-Jiangxi and FujianJiangxi. "Ten lines" are the 10 golden tour lines, which are the main tourist products in the experimentation area [10].

1) Relying on projects: A batch of large projects with excellent types, new formats, distinctive features, strong driving force and good efficiency have become the biggest potential of Zhejiang's tourism development and the direction of transformation and upgrading. In the vast expanse of the Hangjiahu Plain, the key project of Huzhou Anji, Changxin Taihu Shanghai Angel Paradise Park, Jiaxing Hot Springs are tourist destinations people are longing for; In the central area of Zhejiang, Dongyang Hengdian Wan Garden, Quzhou Singapore (Yihuai Park) ecological health leisure valley, Longyou Rosewood Home Furnishing,and other projects are also plugged into the wings of 13th Five-Year Plan; and in the south of Zhejiang, Lishui Qianxia Lake tourism complex, Jinyun Xiandu scenic area project, Wenzhou Yandang Shan-
Nanxi River scenic area project and other projects are enrolled in the 13th Five-Year Plan [11]. These projects promote the related attractions even point into line, accumulation into blocks with large scenic areas at the core.

2) Connecting with platforms: 13th Five-Year Plan points out that we should make Zhejiang a pilot area of China's reform and innovation, a leader of transformation and upgrading of tourism, and a internationally renowned tourist destination. This requires Zhejiang not only build large projects, but also set up a large platform to further enhance the competitiveness. "Small and Beautiful "special towns, distinctively style tourist towns, together with the high-level tourist resorts and scenic spots cluster four large platforms of Zhejiang tourism industry [13]. In addition, we must cultivate large enterprises platform for a new round of investment.

\section{CHALLENGES AND FUTURE OPPORTUNITIES}

Although the tourism has achieved significant development in Zhejiang, Anhui, Fujian and Jiangxi Provinces with the introduction of the policy of reform and opening-up, especially during the 12th Five-Year, it also has faced some challenges for ecotourism. First, quantitatively determining the level of "greenness" or "ecology"(such as the certification of sunshine kitchen, green hotels) and evaluating or assessing their participation are both costly and difficult to ascertain. Second, sometimes, ecological benefits and economic benefits are difficult to balance. The third challenge is financial sustainability for accreditation projects and benchmarking [14].

China has a long history, a splendid culture and enchanting natural scenery. Zhejiang, Anhui, Fujian and Jiangxi each have its own uniqueness. All this could be translated into opportunity, advantage and potential for ecotourism development, including: tourism

a) Increased awareness of environment, ecology and

b) Rapidly urbanization and population growth(especially seniors'population) [14];

c) Increased access to new science and technology which advance ecotourism and information exchange(WIFI,VR,GPS) [15].

\section{CONCLUSION}

The Zhejiang-Anhui-Fujian-Jiangxi Ecotourism Cooperation Zone is a significant ecological demonstrative region construction. This paper mainly starts with the two aspects of supply and demand for countermeasures, which are creating special tourism and shaping the tourism brand (demand-side), innovating tourism development mechanism and implementing driving strategy of large scenic area (supply-side). Demand-side and supply-side interact with each other, supporting each other to speed up the construction of the Zhejiang-Anhui-Fujian-Jiangxi Ecotourism Cooperation Zone. It can be concluded that future research of the countermeasures of The Zhejiang-Anhui-Fujian-Jiangxi Ecotourism Cooperation Zone and ecotourism's potential to develop other regional or holistic tourism is now needed. 


\section{REFERENCES}

[1] Yang Yongquan, "Zhejiang, Anhui, Fujian and Jiangxi construct ecotourism cooperation zone with each other", China Travel News, No.2, July 2015.

[2] Tourism Bureau of Zhejiang Province, "Policy interpretation of Opinions on Further Promoting Tourism Investment and Consumption", available at: http://www.tourzj.gov.cn/,December, 2016.

[3] Li Danchao, Chen Jifen, "The province issued views to further promote tourism investment and consumption-how Zhejiang tourism growth", Zhejiang Daily, May 28,2016.

[4] Statistical Communique on national economic and social development of Zhejiang, Anhui, Fujian and Jiangxi Provinces in 2016, available at: http://www.zj.stats.gov.cn/, http://www.ahtjj.gov.cn/, http://www.statsfj.gov.cn/, and http://www.jxstj.gov.cn/,2016.

[5] National Bureau of Statistics of China, available at: http://www.stats.gov.cn/, 2015.

[6] Xie Yanjun "Introduction to Tourism", Publishing House: Northeast University of Finance and Economics Press, August 1,2011.

[7] Baidu Encyclopedia, available at: http://baike.baidu.com/,2017.

[8] Wu Guoqin, "On the Difficulties and Paths of Green Transformation in Tourism", Journal of Henan Normal University, Philosophy and Social Sciences, No.5: 186-188,2015.

[9] Huang Lili, Pan Pan, "Policy interpretation of Tourism Development of 13th Five-Year Plan in Zhejiang Province" , Zhejiang Daily, February 13, 2017.

[10] The State Council, "13th Five-Year Plan Tourism Development Plan, Website",available at:http://www.gov.cn/, December 26, 2016.

[11] Address at the Opening Ceremony of the First World Conference on Tourism for Development,19 May, 2016.

[12] Francesca D’Alessandro,"Green Building for a Green Tourism. A new model of eco-friendly agritourism",Agriculture and Agricultural Science Procedia, pp:201-210,2016.

[13] Li Weigang, "Policy interpretation of opinions on the establishment of tourist style towns by the People's Government of Zhejiang Province",Tourism Bureau of Zhejiang Province, April 1, 2017.

[14] Anna Gibson, Rachel Dodds, Marion Joppe, Brian Jamieson, "Ecotourism in the city? Toronto's Green Tourism Association", International Journal of Contemporary Hospitality Management, Vol. 15, No.6, pp.324-327,2003.

[15] Yang Wei,"Study of implementation of Green tourism in the perspective of low carbon economy -take implementation of green tourism in Shanxi Jincheng city as an example", China University of Geosciences (Beijing),2013. 